\title{
Experiences of community service environmental health practitioners
}

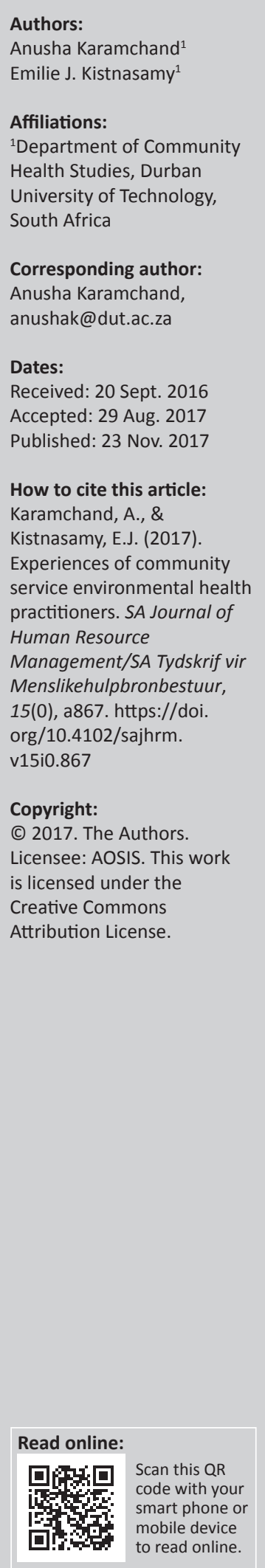

Orientation: The community service initiative, a 1-year placement of health graduates, significantly improved human resource availability in the South African public health sector, even though the process was fraught with challenges. Although experiences in the curative health sector were assessed, the experiences of environmental health practitioners were yet to be studied.

Research purpose: This study assessed the experiences of environmental health practitioners during their community service year.

Motivation for the study: Anecdotal evidence suggested problems with the process. This study endeavoured to identify the challenges whilst taking cognisance of its effectiveness.

Method: A total of $n=40$ environmental health graduates from the Durban University of Technology who had concluded community service completed questionnaires in this crosssectional quantitative study. Descriptive statistics, means and standard deviations were used to analyse the data.

Main findings: The timing of community service placements was critical as $58 \%$ of respondents had to repay study loans. The placement of married respondents (10\%) outside KwaZuluNatal, however, could have had impacts on family structures. Only $68 \%$ felt stimulated by their job functions, and there arose challenges with accommodation and overtime duties. Respondents felt that their tertiary education did equip them and that engagement with senior personnel helped in their professional development. Even though most of the review of the community service year appeared to be positive, a majority of respondents did not intend to continue working or recommending their workplaces. Future career pathing showed that $79 \%$ would prefer to be employed outside the public sector.

Practical and managerial implications: The process needs to be reviewed to strengthen human resource management and enhance retention in the often overloaded and under-resourced South African public health sector.

Contribution: Relevant stakeholders can better plan, communicate and support affected parties through empowering management structures and providing logistical aid.

\section{Introduction}

The community service initiative was a compulsory 1-year placement of most health professionals on completion of their primary diploma or degree in the public sector, failing which they would be unable to enter professional practice (Department of Health, 2011). This initiative significantly improved the availability of human resources and began in 2001 with the compulsory placement of doctors, dentists and pharmacists followed in 2004 by other categories of health professionals (Harrison, 2009).

The initiative had two policy objectives, namely (1) to achieve better distribution of human resources for health (HRH) to underserviced areas and (2) to create an enhanced environment for gaining experience (Report of the Community Service for Health Professionals Summit held on the 22nd April 2015). Given these objectives, South Africa subsequently developed an HRH strategy which also considered the WHO recommendations on the recruitment and retention of health professionals in rural and remote areas (Department of Health, 2011). Table 1 shows the three strategic objectives of the HRH strategy for the health sector (2012/2013-2016/2017) as applicable to community service.

The community service initiative, however, has encountered many challenges as evidenced, for example, by Gurnell (2003) who equated community service to a conscription campaign. Similarly, 
TABLE 1: Human resources for health strategy for the health sector (2012/20132016/2017) as applicable to community service (Department of Health, 2011).

Strategic objective
Strategic Objective 6: Professional
Human Resource Management
Aim

To effectively manage human resources in a manner that attracts, retains and motivates the health workforce to both the public and private sectors in an appropriate balance

Strategic Objective 7: Quality Professional Care

To develop a health workforce that delivers an evidence-based quality service, with competence, care and compassion

Strategic Objective 8: Access in Rural To promote access to health professionals in and Remote Areas rural and remote areas

Source: Department of Health. (2011). HRH strategy for the health sector: 2012/132016/17. Pretoria: Department of Health

although a bit more restrained, community services doctors observed that the placement process and the lack of criteria for approved facilities were problematic but they also felt that in spite of this, their contributions were impacting upon disadvantaged communities (Bateman, 2003). There is still though the question by community health experts about the impact of community service when infrastructure and supervision is often dismal, even if 10 healthcare disciplines saw 11847 graduates through the public sector in 6 years (Bateman, 2004).

Reid (2002) expressed that there was concern in the delivery of community service, particularly in the following areas:

- the disjuncture between academic training and the practicalities evidenced in the public health sector

- the management deficiencies in the public health system

- the annual burden on senior staff who have to orientate, mentor and train each new group

- the alarming number of young health professionals who intend to work overseas.

He further noted that historically, one of these healthcare disciplines, namely environmental health, appeared to be well below average in terms of delivery, particularly in the rural areas where it was most needed.

Agenbag and Gouws (2004) study showed that there were fragmented and poorly distributed environmental health services at a provincial and national level where additionally environmental health practitioners (EHPs) contributed to an already substandard delivery of service by being inappropriately employed. Further, although community service was initiated to solve these issues, numerous concerns on both the side of the employer and the prospective employee arose. These ranged from lack of finance to opening frozen posts to accommodating community service EHPs and the feasibility of employing EHPs who may not be sufficiently equipped to be effective employees. The aspirations and career pathing of the community service EHPs also needed to be determined and whether they were adequately prepared to undertake community service. An added concern was that EHPs that entered community service straight from tertiary institutions have very limited practical experience.

\section{Purpose}

Anecdotal evidence suggested that there were problems with placements and job satisfaction since the introduction of compulsory community service for EHPs. To date, however, and after an intensive literature review, no study was undertaken to identify the actual problem areas or the effectiveness of community service for EHPs in South Africa. The purpose of the study, therefore, was to assess the experiences of EHPs during their community service year.

\section{Literature review}

\section{Introduction}

The 1-year period of compulsory community service for health professions was initially implemented for medical doctors, dentists and pharmacists who were routinely allocated for a 12-month period of service in public institutions that had been registered for community service (Reid, 2002). The regulation relating to EHPs was promulgated by an amendment under Government Notice R69 in January 2002 with the effective date being from the year 2003. Other professional groups included were physiotherapists, occupational and speech therapists, clinical psychologists, dieticians and radiographers. The main objective of community service was to ensure improved provision of health services to all citizens of South Africa. In the process, it also provided these newly qualified professionals with an opportunity to develop skills such as acquiring appropriate knowledge and behaviour patterns as well as critical thinking that will help their professional development (Reid, 2002). Additionally, if these various categories of health professionals failed to complete or were not placed for community service, they could not be registered by the Health Professional Council of South Africa (HPCSA) to practise in the public sector (National Department of Health, 2004).

\section{Application and allocation process}

All graduates and final year students, including those that had participated in this study, had completed a standard application form issued by the National Department of Health $(\mathrm{NDOH})$ and returned these to their tertiary institutions (National Department of Health, 2004). Each applicant was allowed five choices of approved or gazetted health facilities. Each tertiary institution then submitted the completed forms to the NDOH for processing. These forms are sorted according to provinces who had initiated the allocation process on a needs basis. Unplaced applications were returned to the $\mathrm{NDOH}$. The NDOH held a second allocation meeting based on pending vacancies in other provinces. A second list of available or vacant posts in other provinces was circulated to tertiary institutions for students to reapply. The same allocation process started again. When chosen, the applicant was issued with a letter of employment or a contract. Nonplaced students chose to either further their studies if finances allowed them to do so or stayed at home. Others sought casual labour or started working in the private sector.

\section{Shortages of environmental health practitioners mainly in rural and homelands}

Agenbag and Gouws (2004) found that there was a huge shortage of EHPs especially in the rural areas (former 
homelands) where there were between 55\% and 100\% understaffed environmental health departments. These findings appeared to be consistent with data provided by the South African Health Systems Trust (1999) which showed that there had been no substantial increase in the number of EHPs employed nationally since 2005. Further, there was no data available on the distribution of environmental health personnel between rural and urban areas. Another concern that was expressed was the mismanagement of environmental health services where EHPs, for example, were being used in functions unrelated to environmental health. This was further exacerbated by lack of expertise and inconsistent provision of services between districts and provinces.

\section{Communique by the Department of Health}

A communique by Cheyne (2007), assistant manager delegated for the placement of community service personnel in KwaZulu-Natal, under the direction of the Department of Human Resource Practices in the Department of Health, noted that with the devolution of power to district level the continued placement of community service was proving problematic in that these devolved authorities were, in effect, autonomous and not empowered to take on community service. The major area of concern was financial constraints, and despite Treasury making funds available, this was not necessarily a standardised procedure. Further, two areas that were of concern was the availability of office space and EHPs not having their driving licences, which made them ineffective as additional funds were needed to provide drivers. Additionally, environmental health services had received minimal attention, because of a longer than anticipated transformation process and a focus on curative health services contributing to less than required resources allocated to environmental health. An additional bias was that urban environments received more attention than rural areas which in turn contributed to a restriction in the building of capacity and resources. Cele (2012) also voiced the concern that since 2007, the placement process for EHPs was a serious challenge for the Department of Health who subsequently amended the Regulation for Community Service which allowed municipalities to employ community service EHPs.

\section{Method}

\section{Research approach}

This cross-sectional study was conducted during MayOctober 2013 and undertaken in partial fulfilment of an Honours research project in the field of Office Management and Technology at the Durban University of Technology (DUT). Respondents were recruited as per the inclusion criteria noted under the Measures section. After all ethical procedures were complied with, respondents were assigned self-administered questionnaires via electronic mail or personal collection. Returned and completed questionnaires were checked for errors and the information was captured and analysed using Stata 13.1.

\section{Measures}

\section{Participants}

The population consisted of all former environmental health graduates from the DUT. Additionally, inclusion criteria were as follows: EHPs who were resident and working in South Africa, had completed community service in South Africa and were graduated or current Environmental Health B-Tech (Honours) students at DUT.

\section{Measuring instrument}

The data collection instrument was a questionnaire that was developed based on similar studies in the health field (Parker et al., 2011; Reid, 2001). It consisted of six sections: (1) socio-demographic characteristics of respondents (with information required ranging from current profession, demographics to tertiary institution and year that the diploma was received); (2) community service placements (including questions on year placed, whether in or outside KwaZulu-Natal, employer, allocation process and convenience of workplace); (3) community service job functions (closed questions concerning job stimulation, decision-making powers, provision and satisfaction with accommodation and overtime duties, and remuneration thereof); (4) the community service year consisted of two categories: (1) a review of the community service year and (2) factors that contributed to professional development. Respondents answered using the Likert Scale ranging from $1=$ strongly agree; 2 = agree; $3,=$ disagree to 4 , = strongly disagree for a 12-item and 6-item scale, respectively; (5) future career plans (included questions on where do you plan on working once you have completed community service and at what stage of your education or career did you decide on these plans) and (6) suggestions to improve the environmental health community service programme.

\section{Research procedure}

Potential participants were recruited via electronic media. Sixty potential participants responded. If they wished to participate in this study, each was given a letter of information and an informed consent form to complete. The consent form outlined the motivation and purpose of the study and noted that any data collected will be treated with confidentiality. All participants that met the inclusion criteria and had signed the informed consent completed a self-administered questionnaire. The final sample size was $n=40$.

\section{Statistical analysis}

The capturing, cleaning and coding of data was performed using Stata 13.1. Descriptive statistics were used to determine the socio-demographic characteristics of the respondents. After initial descriptive analysis, frequency distribution of categorical variables was calculated. For the review of the community, service year and the factors that contributed to professional development, means and standard deviations were calculated. 


\section{Results \\ Socio-demographic characteristics of respondents}

As noted in Table 2, the majority of the respondents (57\%) were EHPs with 78\% African, $60 \%$ single and $75 \%$ female. Seventy-five per cent of respondents were in the category of 19-30 years with 48\% resident in Durban. No respondents had received study bursaries but 58\% had taken a financial loan to pay for their studies which would be paid back on completion of their studies. There were plans by $45 \%$ of respondents to repay their financial obligations, whereas $26 \%$ undertook service payback.

\section{Community service placements}

Majority of community service placements (95\%) occurred between 1 and 2 years after student graduation with the exception of $5 \%$ of the respondents. The $5 \%$ graduated prior

TABLE 2: Socio-demographic characteristics of respondents $(n=40)$.

\begin{tabular}{|c|c|c|}
\hline Socio-demographic characteristics & Frequency & $\%$ age \\
\hline \multicolumn{3}{|l|}{ Current profession (end 2013) } \\
\hline Environmental Health Practitioners & 23 & 57.50 \\
\hline Occupational Health \& Safety Specialist & 10 & 25.00 \\
\hline Waste Management Officer & 1 & 2.50 \\
\hline Other & 6 & 15.00 \\
\hline \multicolumn{3}{|l|}{ Gender } \\
\hline Male & 10 & 25.00 \\
\hline Female & 30 & 75.00 \\
\hline \multicolumn{3}{|l|}{ Marital status } \\
\hline Married & 15 & 37.50 \\
\hline Single & 24 & 60.00 \\
\hline Other & 1 & 2.50 \\
\hline \multicolumn{3}{|l|}{ Race } \\
\hline African & 31 & 77.50 \\
\hline Indian & 9 & 22.50 \\
\hline \multicolumn{3}{|l|}{ Age group (years) } \\
\hline 19-30 & 30 & 75.00 \\
\hline $31-40$ & 9 & 22.50 \\
\hline $41-50$ & 1 & 2.50 \\
\hline \multicolumn{3}{|l|}{ Home town } \\
\hline Durban & 19 & 47.50 \\
\hline South Coast & 8 & 20.00 \\
\hline North Coast & 5 & 12.50 \\
\hline Other & 8 & 20.00 \\
\hline \multicolumn{3}{|l|}{ Primary language } \\
\hline English & 9 & 22.50 \\
\hline Xhosa & 2 & 5.00 \\
\hline Zulu & 29 & 72.50 \\
\hline \multicolumn{3}{|l|}{ Tertiary institution where diploma received } \\
\hline Durban University of Technology & 27 & 67.50 \\
\hline Mangosuthu University of Technology & 12 & 30.00 \\
\hline Other & 1 & 2.50 \\
\hline \multicolumn{3}{|l|}{ Year diploma received } \\
\hline 2006 and before & 12 & 30.00 \\
\hline 2007 & 7 & 17.50 \\
\hline 2008 & 4 & 10.00 \\
\hline 2009 & 5 & 12.50 \\
\hline 2010 & 8 & 20.00 \\
\hline 2011 & 3 & 7.50 \\
\hline 2012 & 1 & 2.50 \\
\hline
\end{tabular}

to 2007 and in 2007 but were only, respectively, placed in 2011 and 2010 . From the $78 \%$ of respondents who were placed in KwaZulu-Natal, $18 \%$ were male and $60 \%$ female, with $27 \%$ married and $50 \%$ single. Those placed outside the province comprised $7 \%$ male and $15 \%$ female, with $10 \%$ married and $10 \%$ single. Respondents were employed as follows: municipalities $=48 \%$, Department of Health $=50 \%$ and $2 \%$ did not respond (Table 3). No respondents received a rural allowance.

\section{Community service job functions}

Although $90 \%$ of respondents were mainly engaged in fieldwork, $10 \%$ did spend the majority of their time undertaking administrative duties. Only $68 \%$ felt stimulated by their job functions. Decision-making powers were afforded to $50 \%$ of respondents in carrying out their job functions. Employers provided accommodation for 23\% of the community service employees but $56 \%$ were not satisfied with the provided accommodation. Special overtime duties were performed by $33 \%$ of the participants with only $23 \%$ receiving overtime pay for doing so.

\section{The community service year}

The community service year was divided into two categories, namely a review of the year and factors that contributed to professional development. Tables 4 and 5 show lists of items in the two categories with their accompanying means and standard deviations.

In Table 4, results showed that participants highly disagreed that they will stay on working at the same workplace (mean $=2.94, \mathrm{SD} \pm 1.07)$ and that their attitudes towards CS did not become more negative because of their experiences $($ mean $=2.93, \mathrm{SD} \pm 1.02)$. High agreement was noted in tertiary education equipping respondents for their placements (mean $=1.58, \mathrm{SD} \pm 0.71$ ) and on feelings of having contributed towards the health of the communities that they served $($ mean $=1.75, \mathrm{SD} \pm 0.71)$.

In Table 5, results showed that participants highly disagreed that working overtime contributed to their professional development (mean $=2.82, \mathrm{SD} \pm 0.92$ ), whereas it was highly agreed that mentorship and support (mean $=1.90, \mathrm{SD} \pm 0.79$ ), support from management $($ mean $=1.90, \mathrm{SD} \pm 0.81$ ) and engagement with senior EHPs (mean $=1.90, \mathrm{SD} \pm 0.85$ ) did enhance professional development.

TABLE 3: Community service placements.

\begin{tabular}{lcccccc}
\hline Community service placements & \multicolumn{3}{c}{ Yes } & & \multicolumn{3}{c}{ No } \\
\cline { 2 - 3 } \cline { 5 - 6 } & $\boldsymbol{n}$ & $\mathbf{\%}$ & & $\boldsymbol{n}$ & $\mathbf{\%}$ \\
\hline $\begin{array}{l}\text { CS placement was one of the top } \\
\text { five choices }\end{array}$ & 30 & 75 & & 10 & 25 \\
$\begin{array}{l}\text { Satisfied with the allocation process } \\
\begin{array}{l}\text { Workplace was situated at a } \\
\text { convenient place }\end{array}\end{array}$ & 25 & 63 & & 15 & 37 \\
$\begin{array}{l}\text { Impacted on travel time to and } \\
\text { from work }\end{array}$ & 7 & 63 & & 15 & 37 \\
\hline
\end{tabular}


TABLE 4: Review of the community service year.

\begin{tabular}{ll}
\hline Review of the community service year & Mean \pm SD \\
\hline 1. My tertiary education equipped me for the placement & $1.58 \pm 0.71$ \\
2. I was oriented by the staff on arrival & $2.00 \pm 0.81$ \\
\hline $\begin{array}{l}\text { 3. I experienced supervision, mentorship and support whilst } \\
\text { doing CS }\end{array}$ & $1.88 \pm 0.79$ \\
4. I received support from my management & $2.00 \pm 0.91$ \\
$\begin{array}{l}\text { 5. My seniors have been available and accessible when I needed } \\
\text { assistance }\end{array}$ & $1.93 \pm 0.89$ \\
$\begin{array}{l}\text { 6. My attitude towards CS has become more negative because } \\
\text { of my experience }\end{array}$ & $2.93 \pm 1.02$ \\
\hline $\begin{array}{l}\text { 7. I feel that I have contributed towards the health of the } \\
\text { community that I served }\end{array}$ & $1.75 \pm 0.71$ \\
\hline $\begin{array}{l}\text { 8. I had the necessary supplies and equipment available to do } \\
\text { my job }\end{array}$ & $2.56 \pm 0.97$ \\
\hline 9. I received my salary and allowance on time & $1.79 \pm 0.98$ \\
$\begin{array}{l}\text { 10. My workplace environment increased the risk to my } \\
\text { personal safety }\end{array}$ & $2.73 \pm 1.04$ \\
\hline $\begin{array}{l}\text { 11. I intend to stay on working at the same workplace } \\
\text { 12. I would recommend my workplace to future EHPs }\end{array}$ & $2.94 \pm 1.07$ \\
\hline
\end{tabular}

$\mathrm{CS}$, Community service; EHPs, environmental health practitioners.

TABLE 5: Factors that contributed to professional development.

\begin{tabular}{ll}
\hline Factors that contributed to professional development & Mean \pm SD \\
\hline 1. Level of workplace & $2.03 \pm 0.84$ \\
2. Working overtime & $2.82 \pm 0.92$ \\
3. Mentorship and support & $1.90 \pm 0.79$ \\
4. Support from management & $1.90 \pm 0.81$ \\
5. Engagement with senior EHPs & $1.90 \pm 0.85$ \\
6. Engagement with peers & $1.97 \pm 0.90$
\end{tabular}

EHPs, environmental health practitioners.

\section{Future career plans}

When asked about their future career plans after the completion of the community service year, $46 \%$ of respondents preferred working in the private sector, whereas $33 \%$ would choose to go overseas if given the opportunity. A further $13 \%$ choose the public sector with $5 \%$ of these hoping to specialise and 3\% wanting to work in rural development. Three per cent chose to work in non-governmental organisations, whereas 5\% were undecided. The majority of participants $(85 \%)$ decided on their future career pathing during the CS year.

\section{Some suggestions to improve the environmental health community service programme}

\section{Nationally}

Respondents requested improved communication between EH graduates and the Director General or community service facilitator and felt that community service placement should rather be co-ordinated at a national level. In order to ensure that graduates were placed timeously and appropriately, it was suggested that other approved facilities be sought to offer this service, for example, clinics, hospitals and relevant industries.

\section{Placement}

The system of placement must be changed where employment should be based on qualifications and nepotism should be eradicated. It was preferred that community service EHPs be placed in the districts closest to their homes.

\section{Workplace}

These suggestions were divided into three categories. The first was management and job functions. Support should be provided from management in the form of, for example, assigning supervisors to assist with mentoring community service EHPs and that the subordinate should be treated with dignity. Administrative duties should not be the main job function, but rather community service EHPs would prefer being in the field assessing health-related issues. Secondly, logistically, proper equipment must be made available for community service EHPs to perform their tasks and duties and also allow those who have drivers' licences to drive government vehicles. Suitable accommodation should be provided for EHPs living away from their homes. Thirdly, development programmes through workshops and seminars, should be offered.

\section{Discussion \\ Outline of the results}

\section{Community service placements}

Community service placements for the sample group occurred 1-2 years after graduation. This timing was vital, as a large percentage (58\%) had taken financial loans to pay for their studies. Timeous placement would have assisted in timeous loan payments and not created an added financial burden to the graduate and their families. The placement of married EHPs (10\%) outside KwaZulu-Natal, however, could have had negative financial, social and emotional impacts on the marital and family structures as the incumbents may have been only able to visit their homes on an irregular basis. Therefore, factors that could have influenced choice of placement for community service EHPs were most probably similar to that of South African occupational therapists where family contact and proximity to home were vital (Lebogang, Erasmus, Di Rago, Hooper \& O’Reilly, 2014). Nemutandani, Maluleke and Rudolph (2006) noted in their study, however, that there was difficulty in placing community service doctors at hospitals of their choice as many preferred working and living in big cities which had good services and infrastructure, which then left the rural areas and former homelands with a severe shortage of health professionals.

It is therefore significant that the majority of our respondents had their community service placement as one of their top five choices and were satisfied with the allocation process, that the workplace was situated at a convenient place and that travel time to and from work was not greatly impacted upon. This speaks of good planning and allocation facilitation by the relevant environmental health governmental bodies. Note must be taken, however, of the time period of our sample groups' placements as there could have arisen subsequent changes or challenges since then. These findings, however, are contrary to that of Mashigea, Oduntanb and Rampersad (2013) where community service optometrists experienced poor remuneration and had concerns about personal safety, transport and accommodation. These concerns were also 
evidenced in Hatcher, Onah, Kornik, Peacocke and Reid's (2014) study where a high percentage of medical and dental community service officers reported accommodation as unsatisfactory $(43 \%)$, their personal safety as lacking $(66 \%)$ and remuneration as unfair $(46 \%)$.

\section{Review of the community service year}

Our respondents agreed that their tertiary education did equip them for placement. This equipping occurs through a 100 days of work-integrated learning (WIL) programme over their 3-year diploma cycle. WIL is often conducted in collaboration with municipalities and other pertinent stakeholders. These in the field hands on training together with the theory taught in class would have greatly enhanced and contributed towards their readiness for entering the environmental health profession. Similarly, nurses perceived themselves as being well prepared for the year of community service as regards knowledge, skills and ability to administer nursing care (Govender, Brysiewicz \& Bhengu, 2015). Conversely, Nkabinde, Ross, Reid and Nkwanyana (2013) in their study, assessing whether internship training adequately prepared South African medical graduates for community service, found that critical gaps in knowledge and skills in paediatrics, orthopaedics, anaesthetics and obstetrics existed. Additionally, $75 \%$ of their respondents expressed a need for additional training in the disciplines of ear, nose and throat, urology, ophthalmology and dermatology. Also, Roziers and Ramugondo (2014) suggested that for nurses, their curriculum should include structured training in conflict management, assertiveness and practical ethics. These suggestions are also important for the environmental health field and where relevant can only add value to improving the community service year.

It was notable that in our study even though most of the review of the community service year appeared to be positive, a majority of respondents did not intend to stay on working at the same place or recommending their respective workplaces to future EHPs. This now creates a disconnection because if most aspects of the community service were positive, then it should follow that community service EHPs would like to continue working and recommend their workplaces. The reasons for doing this were not explored in this study but some of the suggestions to improve the community service programme as put forward by the respondents may better speak to this. Further, the majority of participants decided on their future career pathing during their community service year, and nearly, 79\% would prefer to be employed outside the public sector. Given the critical human resource need of EHPs to be employed in the public sector, this does not bode well for the future of the environmental health profession. These results may also be consistent with Hatcher's et al. (2014) findings which showed that a small majority $(66 \%)$ would recommend their community service facility to others, but that only one-third (34\%) intended to stay at the same facility in the coming year.

\section{Factors that contributed to professional development}

Mentorship, support and engagement with senior EHPs helped in the professional development of community service EHPs. These are critical contributory factors as community service is the first key entry point into the profession by new graduates. Support, affirmation, motivation, critical thinking, logistical support and technical expertise by other staff members can only contribute to the upliftment of this critical human resource in the workplace. This is evidenced in studies undertaken of community service in other health professions by Reid (2002), Pillay and Harvey (2006), Visser, Marais and du Plessis (2006), Khan, Knight and Esterhuizen (2009), Ross and Reid (2009) and Parker et al. (2011). Further, Mashigea et al.'s (2013) study noted that community service optometrists improved their technical and clinical skills and enhanced their confidence, personal and social skills. Hatcher et al.'s (2014) study showed that overall satisfaction with community service training and mentorship, with supervision, management and practical concerns during the community service year and that a majority of participants reported that they had developed professionally. The level of the workplace and working overtime, however, were two factors that community service EHPs felt did not contribute sufficiently to their professional development. This could be attributed to how they were treated in the workplace by management or professionals in authority. Similar feelings were expressed in studies by Reid (2001) and Hatcher et al. (2014). Other health professions had some additional factors that should be taken into consideration. In Govender et al.'s (2015) study, there was limited orientation and support and nurses experienced problems of acceptance by fellow professional nurses, whereas in Paterson, Green and Maunder's (2007) study, community service dieticians (CSDs) experienced a lack of supervision and support, lack of preparedness of the institutions receiving them, a lack of clarity of the part of the CSD and a lack of teamwork. In her article on the reflections of a community service, clinical psychologist, Swarts (2013) noted that clinical guidance was minimal because of insufficient supervisory capacity.

\section{Practical implications}

It is important that concerns of our respondents and their suggested solutions are noted, discussed and implemented as best seen fit by the relevant government bodies and their associated stakeholders. The community service programme in the health sector has noble objectives that can only be achieved by a feasible, transparent and timely implementation process. It is necessary for government to review each aspect of the programme from inception (when students complete their necessary forms) to completion (on conclusion of the community service year). This review process will help manage this vital human resource of community service personnel better, especially if government is amenable to critically evaluate the pros and the challenges and to take heed of the suggested solutions of community service personnel. This transparent process can only strengthen the community service 
programme and enhance human resource management and retention in the often overloaded and under-resourced South African health sector. Note should also be taken of the implications associated with community service EHPs greater preference to not only work in the private sector, but that $33 \%$ of our sample group would choose to work overseas if the opportunity presents itself. This type of statistic was also noted by Reardon and George (2014) who found that doctors and nurses had a higher disposition to moving overseas, especially among those who had had a frustrating and challenging community service year. These frustrations were echoed by Miguel Desroches, a Wits-educated and former Tygerberg Hospital medical intern who complained to the Constitutional Court about provincially dysfunctional administrations and dismal working conditions under which he and his peers struggled daily (Bateman, 2014).

\section{Limitations and recommendations}

\section{Limitations}

Environmental health graduates from other tertiary institutions were excluded because of logistical issues.

\section{Strengths}

This appears to be one of the first studies of this nature conducted among community service EHPs. It allowed for input from the allocation process through to the conclusion of community service and beyond, especially as regards future career pathing.

\section{Future research}

Future research could delve more deeply into reasons behind some of the quantitative aspects covered in this study. This could be carried out using qualitative or mixed methods to gain a greater understanding of some of the frustrations and challenges experienced in the community service year by graduates. It would also enhance best practice to obtain the views of the employer in this regard. Feasible interventions could be piloted by the government and relevant stakeholders and reviewed thereafter to see if these can be implemented countrywide in environmental health divisions. There also should be an audit of the management and logistical resources available in the approved health facilities so that note can be taken of the challenges faced by the employer when endeavouring to empower community service personnel.

\section{Conclusion}

This study has shown that community service EHPs have gained much from their respective placements. As in any system, however, there is still room for improvement. The onus also falls on community service personnel to make their voices known using the HPCSA and any available environmental health fora to develop feasible strategies pertaining to communication, implementation, human resources, logistics, management and leadership as utilised in the community service year.

\section{Acknowledgements}

The authors acknowledge the assistance, support and technical expertise, and intellectual input of all respondents, Mrs K. Moodley, Mr P. Karamchand, Prof. R. Bhagwan, Prof. P. Reddy, Mrs R. Ramsingh, Dr M. Rajkoomar, Ms R. Devraj and Mrs L. Meyers.

\section{Competing interests}

The authors declare that they have no financial or personal relationships that may have inappropriately influenced them in writing this article.

\section{Authors' contributions}

A.K. was the project leader and responsible for project design and data collection. E.J.K. made conceptual contributions and undertook the statistical analyses. A.K. and E.J.K. wrote the manuscript.

\section{References}

Agenbag, M., \& Gouws, M. (2004). Redirecting the role of environmental health in South Africa. Organised by SB Conferences. Retrieved July 01, 2015, from www. kharahais.gov.za/files/health/011.pdf

Bateman, C. (2003). Still getting community service right. SAMJ, 93(1), 16.

Bateman, C. (2004). Community service six years on.... SAMJ, 94(6), 408-409.

Bateman, C. (2014). Community service doctors 'slaves to the State' - Court challenge. SAMJ, 104(4), 263-265. https://doi.org/10.7196/SAMJ.8084

Cele, A. (2012). Community service environmental health practitioners. Environmental Health 2012. Newsletter for the Professional Board for Environmental Health Practitioners. 2p.

Cheyne. (2007). Communication. Natalia, Pietermaritzburg: Department of Health Human Resources Department.

Department of Health. (2011). HRH strategy for the health sector: 2012/13-2016/17. Pretoria: Department of Health.

Govender, S., Brysiewicz, P., \& Bhengu, B. (2015). Perceptions of newly-qualified nurses performing compulsory community service in KwaZulu-Natal. Curationis, 38(1), Art. \#1474, 1-8. https://doi.org/10.4102/curationis.v38i1.1474

Gurnell, D.R. (2003). Community service - Or conscription? SAMJ, 93(2), 84.

Harrison, D. (2009, December). An overview of health and health care in South Africa 1994-2010: Priorities, progress and prospects for new gains a discussion document commissioned by the Henry J. Kaiser Family Foundation to Help Inform the National Health Leaders' Retreat Muldersdrift, January 24-26, 2010.

Hatcher, A.M., Onah, M., Kornik, S., Peacocke, J., \& Reid, S. (2014). Placement, support, and retention of health professionals: National, cross-sectional findings from medical and dental community service officers in South Africa. Human Resources for Health, 12, 14. https://doi.org/10.1186/1478-4491-12-14

Khan, N.B., Knight, S., \& Esterhuizen, T. (2009). Perceptions of and attitudes to the compulsory community service programme for therapists in KwaZulu-Natal. South African Journal of Communication Disorders, 56, 17-22.

Lebogang, J.M., Erasmus, A., Di Rago, T., Hooper, J., \& O’Reilly, J. (2014). Factors that influence choice of placement for community service among occupational therapists in South Africa. South African Journal of Occupational Therapy, 44(1), 36-41.

Mashigea, K.P., Oduntanb, O.A., \& Rampersad, N. (2013). Perceptions and opinions of graduating South African optometry students on the proposed community service. South African Optometric Association: SAOA, 72(1), 11-18. https://doi. org/10.4102/aveh.v72i1.43

National Department of Health. (2004). National Department of Health Annual Report 2003/2004. Pretoria: National Department of Health.

Nemutandani, M.S., Maluleke, F.R.S., \& Rudolph, M.J. (2006). Community service in Limpopo province. SAMJ, 96(3), 180-182.

Nkabinde, T.C., Ross, A., Reid, S., \& Nkwanyana, N.M. (2013). Internship training adequately prepares South African medical graduates for community service With exceptions. South African Medical Journal, 103(12), 930-934. https://doi. org/10.7196/SAMJ.6702

Parker, W., Steyn, N.P., Mchiza, Z., Wentzel-Viljoen, E., Dannhauser, A., Mbhenyane, X et al. (2011). Challenges for efficient health service delivery: Experiences of dietitians completing their compulsory community service year in South Africa. Public Health Nutrition, 15(8), 1411-1418. https://doi.org/10.1017/S136898 0011003314 
Paterson, M., Green, M., \& Maunder, E.M.W. (2007). Running before we walk: How can we maximise the benefits from community service dietitians in KwaZulu-
Natal, South Africa? Health Policy, 82, 288-301. https://doi.org/10.1016/j. healthpol.2006.09.013

Pillay, A.L., \& Harvey, B.M. (2006). The experiences of the first South African community service clinical psychologists. South African Journal of Psychology, 36 259-280. https://doi.org/10.1177/008124630603600204

Reardon, C., \& George, G. (2014). An examination of the factors fueling migration amongst community service practitioners. African Journal of Primary Health Care \& Family Medicine, 6(1), Art. \#625, 1-9. https://doi.org/10.4102/phcfm.v6i1.625

Reid, S.J. (2001). Compulsory community service for doctors in South Africa - An evaluation of the first year. SAMJ, 91(4), 329-335.

Reid, S.J. (2002). Community service for health professionals: Human resources. In P ljumba \& P. Barron (Eds.), South African health review (pp. 135-160). Durban: Health Systems Trust. Retrieved September 05, 2015, from http://www.hst.org. $\mathrm{za} / \mathrm{sites} /$ default/files/chapter8.pdf Community service dietitians' experiences 1417Report of the Community Service for Health Professionals Summit held on the 22nd April 2015, City of Tshwane. Co-hosted by the Foundation for Professiona Development (FPD), the National Department of Health (NDoH), the University of Cape Town (UCT) and the Africa Health Placements (AHP).
Ross, A., \& Reid, S. (2009). The retention of community service officers at district hospitals in KwaZulu Natal, Eastern Cape and Limpopo Provinces. South African Family Practice, 51, 249-253. https://doi.org/10.1080/20786204.2009.108 73856

Roziers, R.L., \& Ramugondo, E.L. (2014). Newly qualified South African nurses' lived experience of the transition from student to community service nurse: $A$ phenomenological study. The Journal of Continuing Education in Nursing, 45(2):91-100. https://doi.org/10.3928/00220124-20140122-01

South African Health Systems Trust. (1999). South African health review. p. 202. HST Update Issue No 57. Ministry of Health. Retrieved July 01, 2013, from www.hst. org.za/uploads/files/upd57.pdf

Swarts, B. (2013). A community (dis)service: Reflections of a community service clinical psychologist. South African Journal of Psychology, 43(1) 105-115. https:// doi.org/10.1177/0081246312474420sap.sagepub.com

Visser, J., Marais, M., \& du Plessis, J. (2006). Experiences and attitudes of dietitians during the first compulsory community service year. South African Journal of Clinical Nutrition, 19, 10-17. https://doi.org/10.1080/16070658.2006.1173 4084 